\title{
DHFMA Method for Dynamic Thermal Property Measurement of PCM-integrated Building Materials
}

\author{
Nitin Shukla ${ }^{1}$. Jan Kosny ${ }^{1}$
}

Published online: 9 April 2015

(C) Springer International Publishing AG 2015

\begin{abstract}
Research studies have shown improved energy efficiency with the integration of a phase change material (PCM) in the building envelope. An accurate knowledge of dynamic properties of a PCM-integrated building component is critical in establishing its energy saving potential. Differential scanning calorimetry (DSC) is a common method used to characterize PCMs. However, DSC is valid for small and homogenous specimens, rendering it inappropriate for building-scale PCM products that often contain additives. We describe the theory of a recently developed dynamic heat flow meter method (DHFMA) for testing of PCM-integrated products. To fill the lack of test data and a reliable procedure for the DHFMA method, we characterize five PCM-integrated products combining a variety of PCM types with different building elements. The useful data generated is analyzed to develop a general standard test procedure and verify the repeatability of the method.
\end{abstract}

Keywords Phase change material $\cdot$ Dynamic heat flow meter apparatus $\cdot$ Heat capacity $\cdot$ Thermal insulation .

Shape-stabilized PCM $\cdot$ PCM subcooling

\section{Introduction}

A phase change material (PCM) utilizes its latent heat of fusion (melting) for the purpose of thermal storage or temperature

This article is part of the Topical Collection on Built Environment

Nitin Shukla

nshukla@fraunhofer.org

Jan Kosny

jkosny@fraunhofer.org

1 Fraunhofer Center for Sustainable Energy Systems CSE, 5 Channel Center Street, Boston, MA 02210, USA control of an environment or system [1, 2]. PCM is finding increasing applications in the building constructions for its promise with lowering building energy consumption and temperature regulation of the living space [3-6]. The idea is that PCM absorbs part of building heat loads during the daytime as it melts and releases this heat during cooler night-time by freezing, enabling temperature stabilization and control of the living space. Numerical studies and field tests have shown reduced peak-hour loads and time-shifting of peak-demand with the application of PCM in a building envelope [7]. Cooling energy savings of up to $25 \%$ have been demonstrated with the application of PCM in a building [7].

Interestingly, PCM application in buildings predates development of advanced building thermal insulation technologies such as loose fill insulation and plastic foams. One of the first documented applications of PCM in buildings took place in 1940s (http://www.eoearth.org/article/Telkes,_Maria). Last three decades have seen building codes place increasing emphasis on energy efficiency, leading to ubiquitous application of thermal insulations in buildings. On the other hand, until recently, PCM technology found little to no application in building sector due to its higher initial cost compared to thermal insulations, and performance issues such as flammability, loss of phase-change capability over time, and effective containment. In last two decades, technological advancements in PCM material processing, encapsulation technology, phase stabilization methods, and development of fire retardants for PCMs have addressed most of the performance issues persisting PCM technology. Recent research studies have shown that for retrofit projects with preexisting insulation, adding conventional insulation may not always be the most cost-effective solution to improve the thermal and energy performance of the building envelope (http:// apps1.eere.energy.gov/buildings/publications/pdfs/building america/ns/b15_phase_change.pdf) [8] (http://insulright.com/ 
R\%20Value\%20and\%20Economic\%20Thickness.pdf). In fact, above a certain level of pre-existing insulation, application of PCM will be cheaper than the conventional insulation to bring the same amount of reductions in energy consumption. Biobased PCMs, synthesized from vegetable oils and waste food industry oils in a low-cost and environmentally friendly manufacturing process, have the potential to significantly reduce the material cost.

Improved performance and cost-competitiveness of PCM has led to launch of several PCM-integrated building products in recent years-PCM wallboards, PCM-enhanced insulations, etc. An accurate knowledge of the dynamic or phase change properties, mainly phase transition temperature, latent heat, sub-cooling, and hysteresis, of a PCM-integrated component is critical in predicting the energy saving potential of the PCM product on a whole-building scale $[9,10]$. In early applications, a system-scale container with a pure and homogenous PCM would be integrated with a building element, for example, large PCM wall cores, PCM wall tubes. Therefore, it has been a common practice to use the dynamic properties of the pure PCM for energy or thermal performance analysis of a PCM-integrated product. Traditionally, a differential scanning calorimeter (DSC) has been employed to measure dynamic properties of the pure PCM component of a PCM product [11]. However, DSC method is applicable for specimens with typical sizes of millimeter length scale and mass on the order of milligrams. DSC method also requires that specimen is relatively homogeneous in composition.

State-of-the-art PCM products are quite different than the early applications-PCM is included in the building element on a sub-millimeter length-scale, for example, PCM-enhanced gypsum board, shape-stabilized (ss) PCM sheets, and PCMenhanced blown-cellulose insulation. The dynamic thermal properties of these PCM-integrated components is dependent on several, often unknown, factors such as mass fraction of the PCM, heat capacity and thermal conductivity of different parts of the component, and presence of additives (fire retardants, conduction inhibitors, adhesives). In addition, the dynamic properties of PCM itself may change due to surrounding materials and introduction of foreign materials. Therefore, dynamic properties of PCM-integrated component may be significantly different than the one derived using pure PCM dynamic properties. Advanced PCM products are significantly larger in both the length and mass scales, and are often too inhomogeneous in composition to be used as a test specimen in DSC. In addition, DSC system may become unreliable and inaccurate for slow measurements imitating the temperature profile experienced by the building (about $0.1{ }^{\circ} \mathrm{C} / \mathrm{min}$ ) [12, 13]. The data obtained by DSC is often used in computer models to analyze performance of PCM products, leading to significant inaccuracies in the performance evaluation.

Numerical and experimental studies have shown that inclusion of PCM in the building envelope may result in improved building energy performance. However, a detailed knowledge of dynamic properties of the PCM is required to perform the whole building energy simulations. In addition, the dynamic test data is critical in optimizing the distribution and location of the PCM within a building in order to maximize the energy savings.

Keeping in view of the challenges and the need to reliably measure dynamic properties of large-scale PCM-integrated components and products, a heat flow meter apparatus (HFMA)-based method, commonly referred to as the dynamic HFMA or DHFMA, has been developed in late $2000 \mathrm{~s}$ [14-16]. Since its early development, the DHFMA method has been undergoing continuous modifications. There is a lack of availability of dynamic property data for common PCM products in scientific literature [15-17]. In addition, there is a need to investigate complex PCM systems that exhibit multiple peaks or significant subcooling to be able to determine the limitations and improve the measurement capability of the method. The objective of this paper is to describe the theory and present dynamic property data on a variety of PCMintegrated building products, and develop a test procedure to accurately characterize any PCM product. This will serve advancing this method, allowing scientific and engineering community access to a reliable and accurate measurement tool for PCMs and PCM-enhanced products.

\section{DHFMA Principle}

In principle, the DHFMA method is a step DSC method that can be applied to building-scale specimens. DHFMA is built around an HFMA instrument. The method uses the same thermal information generated by a conventional HFMA instrument, but utilizes it in a different way to determine dynamic properties. A conventional HFMA instrument measures temperature and heat flux at a specified time interval, and uses this information to determine steady state and thermal transmission properties of a test specimen, as specified by ASTM C518 [18].

A rapid temperature ramp methodology was another test method utilizing HFMA instrument that preceded the development of the DHFMA. This method was first developed to measure dynamic performance of PCM-enhanced fiber insulations. The ramp HFMA method is analogous to the DSC ramp method. Similar to the DSC ramp method, the rapid ramp method has a major drawback that results are temperature ramp rate dependent. The original development of DHFMA was driven to improve the accuracy of the rapid ramp method, while causing minimal modification to the HFMA instrument.

In an isobaric process such as the phase transition, the change in enthalpy $(\Delta H)$ is equal to heat absorbed (heat flow in) or released (heat flow out) during the process $(\Delta Q)$. The heat capacity $\left(C_{\mathrm{p}}\right)$ is the temperature derivative of the enthalpy 
(H) i.e., $C_{P}=\frac{d H}{d T}$. Assuming there is a linear relationship between enthalpy and temperature for small temperature increment $(\Delta T)$ :

$C_{P}=\frac{d H}{d T} \approx \frac{\Delta H}{\Delta T}=\frac{\Delta Q}{\Delta T}$

In DHFMA method, temperature of a PCM-integrated specimen is changed by a small step, and the resulting heat flow in or out of the specimen is measured during this process. The heat capacity is then determined at the mean temperature using Eq. 1. DHFMA method uses a conventional HFMA instrument containing at least one heat flow sensor on each of the upper and lower isothermal plates. The specimen is placed across these plate assemblies, while sides are designed to be adiabatic. The upper and lower isothermal plate assemblies are held at the same temperature to impose a uniform temperature across the specimen. A step temperature change is then introduced on both plates, and heat flows through the plates are measured until equilibrium is reached, i.e., the heat flow values become negligible. For the step temperature change, change in enthalpy per unit surface area of the specimen is calculated by integrating the heat flow rate measurements over time [11]:

$\left.\left.\left.\left.\Delta H=\Delta Q=\sum\left[\left\{(q U\}_{i}-q U\right\}_{\text {final }}\right)+(q L\}_{i}-q L\right\}_{\text {final }}\right)\right\} \tau\right]$

where $q \dot{U}^{\prime \prime}{ }_{\mathrm{i}}$ and $q \dot{L}^{\prime \prime}{ }_{\mathrm{i}}$ are heat fluxes through upper and lower plates, respectively, recorded at time intervals of $\tau$, while $q \dot{U}^{\prime \prime}$ final and $q \dot{L}^{\prime \prime}$ final are the residual heat flux values on upper and lower plates, respectively, caused by edge heat losses at equilibrium.

The volumetric heat capacity for the PCM-integrated product is determined as follows

$C_{V}=\frac{1}{l} \frac{\Delta Q}{\Delta T}$

where $l$ is the thickness of the specimen.

It is to be noted that the DHFMA method is applicable for heat capacity measurement of any solid or liquid material. Recently, ASTM introduced a test standard $\mathrm{C} 1784$ to measure thermal storage properties of PCM-enhanced products, based on the DHFMA principle and method [19].

\section{Characterization of PCM Products using DHFMA}

We investigated five PCM-integrated building products using the DHFMA to generate valuable dynamic property data and to be able to develop a reliable general test procedure. The five products tested are described below:

\section{PCM-enhanced Gypsum Board}

This product is a 0.5 -in.-thick gypsum board that is enhanced with approximately $25 \mathrm{wt} \%$ of a microencapsulated paraffinic PCM. A LaserComp FOX304 HFMA is employed to characterize the product. FOX200 can accommodate 12 in. $\times 12$ in. and 4 -in.-thick specimens with a test temperature range of -20 to $75{ }^{\circ} \mathrm{C}$. In order to fit the product inside the instrument sample holder, the specimen was cut into a 12 in. $\times 12$ in. dimension. Both melting and solidification (freezing) experiments were conducted to investigate the subcooling and hysteresis effects in the specimen. An earlier DSC test of the microencapsulated PCM showed phase active region of 16 $26^{\circ} \mathrm{C}$ for the $\mathrm{PCM}$; therefore, a temperature range of $6-32{ }^{\circ} \mathrm{C}$ was considered for the DHFMA with temperature step size of $1.5^{\circ} \mathrm{C}$. A wider temperature range than the DSC test was necessary to capture the details of the phase transformation process in the specimen. To examine the repeatability of the DHFMA and the effect of temperature step on results, an additional melting cycle test with non-uniform temperature steps between 1 and $2.5^{\circ} \mathrm{C}$ was performed.

Figure 1 depicts temperature-dependent volumetric heat capacity for two melting and one freezing tests. It can be seen that data points for melting and freezing tests seem to coincide. A negligible subcooling and hysteresis effects are observed - a common feature of paraffinic PCM and highly desired features for a PCM-enhanced building component. Onset of melting and freezing were found to occur at around 18 and $25^{\circ} \mathrm{C}$, respectively, with a broad phase active range of $\sim 8{ }^{\circ} \mathrm{C}$. The sensible heat capacities of the specimen were measured to be approximately 1.15 and $1.05 \mathrm{MJ} \mathrm{m}^{-3} \mathrm{~K}^{-1}$ when PCM was in solid and liquid states, respectively. The heat capacity is found to increase with temperature when PCM is solid, while it remains constant when PCM is melted. The heat capacity for the same temperature points are found to be very similar, verifying the repeatability of the DHFMA method.

\section{PCM-Aerogel Composite}

The product comprised of a thin layer of PCM applied on one surface of a $3 / 8$-in.-thick aerogel blanket. The specimen was prepared by Aspen Aerogel using a proprietary biobased PCM. A FOX304 instrument was used to perform DHFMA testing. DSC tests on pure PCM sample indicated a broad peak in the heat capacity; it was realized that a temperature resolution of less than $1{ }^{\circ} \mathrm{C}$ may be needed to accurately capture the sharp profile of the data. Sensitivity of heat flow transducers is usually compromised below temperature step sizes of around $1{ }^{\circ} \mathrm{C}$, limiting the size of the minimum temperature step to be used at around $1{ }^{\circ} \mathrm{C}$. To improve the temperature resolution, we developed a new method where we used steps of $1.5^{\circ} \mathrm{C}$ to obtain ample sensitivity in the measurement; however, 

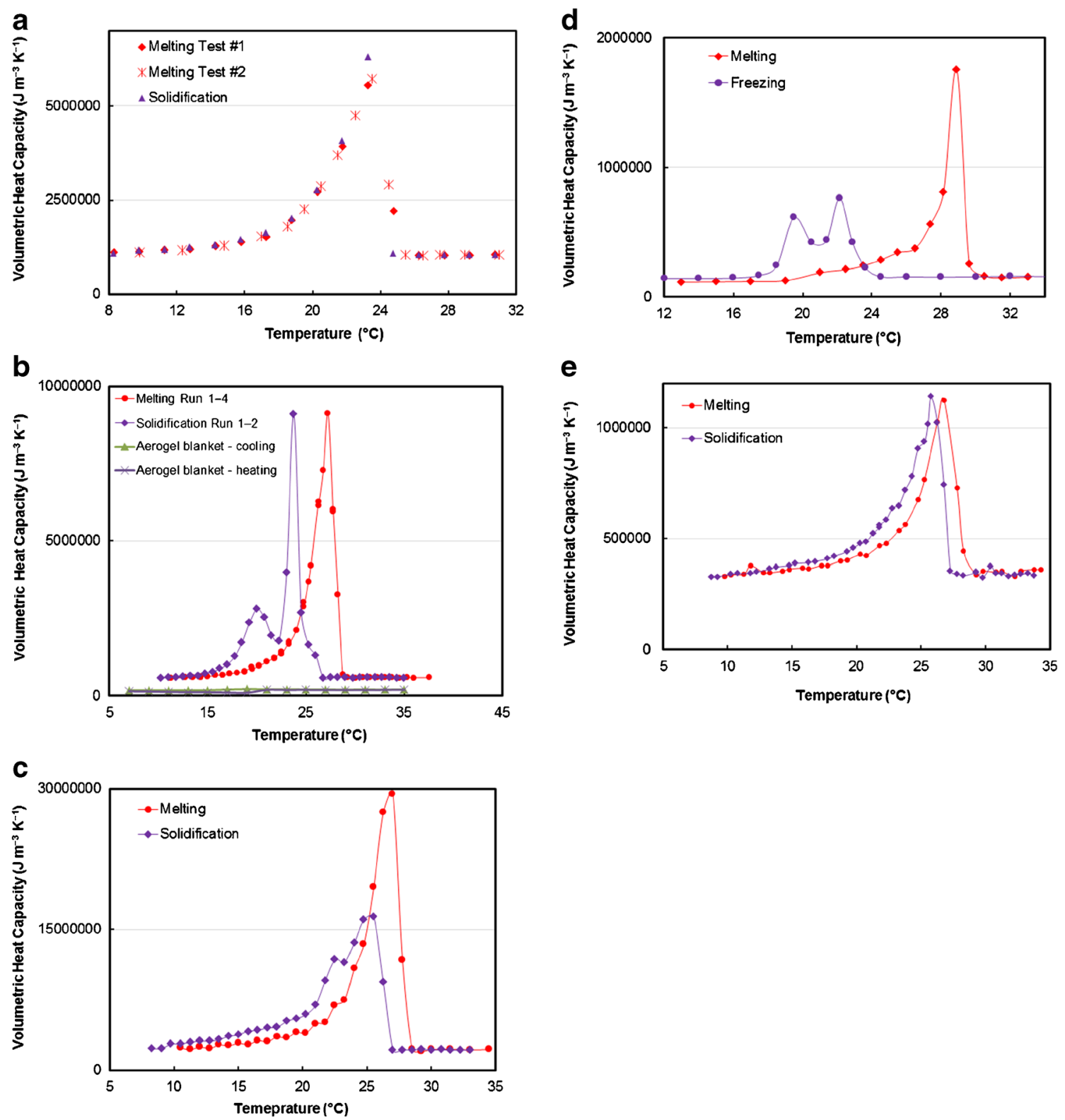

Fig. 1 Volumetric heat capacity as a function of temperature using the DHFMA method a PCM-enhanced Gypsum Board, b PCM-Aerogel composite, c ss-PCM sheet, $\mathbf{d}$ PCM-enhanced blown-cellulose, and e ss-PCM-enhanced blown-cellulose

depending on the desired resolution, additional tests were run that were offset by an amount equal to step size divided by the resolution sought. For example, if a resolution of $0.5^{\circ} \mathrm{C}$ was desired, three tests would be conducted $\left(=1.5^{\circ} \mathrm{C} / 0.5^{\circ} \mathrm{C}=3\right)$ with first set at $\left(T_{0}, T_{0}+1.5, T_{0}+3 \ldots\right)$, second set at $\left(T_{0}+0.5\right.$, $\left.T_{0}+2, T_{0}+3.5 \ldots\right)$, and third test at $\left(T_{0}+1, T_{0}+2.5, T_{0}+4 \ldots\right)$, where $T_{0}$ is some arbitrary starting temperature set-point. Combining the data from these three datasets will essentially provide a resolution of $0.5^{\circ} \mathrm{C}$. Similarly, for a temperature resolution of $0.75{ }^{\circ} \mathrm{C}$, two tests would be conducted $\left(=1.5^{\circ} \mathrm{C} / 0.75^{\circ} \mathrm{C}=2\right)$ with first set at $\left(T_{0}, T_{0}+1.5, T_{0}+3 \ldots\right)$, and second set at $\left(T_{0}+0.75, T_{0}+2.25, T_{0}+3.75 \ldots\right)$.

Three melting and two solidification tests were performed to test the validity of the above proposed approach. Figure $1 \mathrm{~b}$ depicts the profile produced by combining these tests. An effective resolution of 0.5 and $0.75^{\circ} \mathrm{C}$ were obtained for melting and freezing, respectively, as shown in Fig. 1b. Smooth curves were produced by combining the data sets, demonstrating the validity and importance of the method in improving the accuracy of the dynamic data. As evident in Fig. 1b, finer details of the heat capacity curve can be captured by improving temperature resolution in this manner.

The onset of melting occurs at $\sim 19.5^{\circ} \mathrm{C}$, while the peak is observed at $27.25{ }^{\circ} \mathrm{C}$. The solidification cycle is marked by two peaks that occur at 20 and $23.77{ }^{\circ} \mathrm{C}$, suggesting that the PCM used in the PCM-aerogel composite is an inhomogeneous mixture of two (or more) different chemical compounds with slightly different freezing temperature. Melting and 
solidification profiles differ significantly both in the magnitude and the shape with a sub-cooling of $\sim 3.5^{\circ} \mathrm{C}$. One melting test was repeated, and no difference in heat capacity data was observed, suggesting good repeatability of the DHFDMA method.

\section{Shape-stabilized PCM Sheet}

This product is a paraffin derived from biological wastes that is stabilized in a polymer matrix and produced in sheet rolls of 1-mm thickness. A LaserComp FOX200 HFMA system is utilized for the characterization. FOX200 can accommodate 8 in. $\times 8$ in. and 2-in.thickness specimens with a test temperature range of -20 to $85{ }^{\circ} \mathrm{C}$. To be able to fit into HFMA instrument, $20 \mathrm{~cm} \times 20 \mathrm{~cm}$ samples were cut from the sheet roll. To improve signal-to-noise, four such samples were stacked to create a 4-mm-thick test sample.

DSC experiments suggested a need for resolution of less than $1{ }^{\circ} \mathrm{C}$ in order to accurately capture the contours of the heat capacity curve. Following the procedure described in the section "PCM-Aerogel Composite," two tests were performed for melting and freezing each, providing an effective resolution of $0.75^{\circ} \mathrm{C}$.

\section{PCM-enhanced Blown-Cellulose}

The product is produced by blown mixing $20 \mathrm{wt} \%$ of a biobased PCM with cellulose insulation. Fox304 system was used for the testing. A $12 \mathrm{in.} \times 12$ in. thin foam frame was constructed to hold blown PCM-enhanced cellulose sample. Multiple tests with uneven temperature steps were conducted and combined to achieve an effective resolution of around $0.75{ }^{\circ} \mathrm{C}$ near the peaks. A melting peak is observed at around $28.9^{\circ} \mathrm{C}$, while two peaks in freezing are observed at 22.15 and $19.5^{\circ} \mathrm{C}$. A large subcooling of almost $7^{\circ} \mathrm{C}$ is found, a typical feature of biobased PCMs. Two peaks are indicative that PCM is a mixture of two (or more) pure PCMs.

\section{ss-PCM-enhanced Blown-Cellulose}

This product is composed of $30 \mathrm{wt} \%$ blend of a uniformly dispersed ss-PCM pellets with cellulose insulation. Blown cellulose samples were prepared at Advanced Fiber Technology, Inc. (AFT) facility. The pellets were 1-3-mm long in size. A FOX200 HFMA system was used to measure volumetric heat capacity of the mixture as a function of temperature. An 8 in. $\times 8$ in. thin foam frame was fabricated to contain blown-cellulose sample. Two tests each for melting and freezing were performed to obtain temperature resolution of $0.75^{\circ} \mathrm{C}$. Figure 1e shows that melting and freezing peaks occurs at $\sim 27$ and $25.5{ }^{\circ} \mathrm{C}$, respectively, exhibiting a subcooling of around $1.5^{\circ} \mathrm{C}$.

\section{Conclusions}

Until recently, differential scanning calorimeter (DSC) has been the only available method to determine the dynamic properties of a PCM and PCM-integrated building products. DSC method is extremely limited in characterizing building-scale PCM products as it is valid only for small and homogeneous specimens, and is incapable of capturing the complexities observed in large-scale building components. DHFMA is a recently developed method for dynamic property measurement of system-scale PCM and products. There is a need to characterize different types of PCM products and develop a general method for the DHFMA method before it can gain acceptance among scientific and research community. In this study, we describe the principle behind this method and present dynamic property data for five different types of PCM-integrated materials. The data generated is used to formulate a general test procedure for the DHFMA method.

In principle, heat flow signals from heat flow sensors are integrated over time to determine enthalpy change during a temperature step change. Five products-PCM-enhanced Gypsum Board, PCM-Aerogel Composite, ss-PCM Sheet, PCM-enhanced blown-cellulose, and ss-PCM-enhanced blown-cellulose - were tested for their dynamic properties using the DHFMA method. These products provided a combination of a variety of PCM forms such as paraffin, biobased, and ss with different building components such as insulations and wallboard. To improve the temperature resolution, a new testing procedure was developed where tests were performed using temperature steps of $1.5^{\circ} \mathrm{C}$ to obtain ample sensitivity in the measurement. However, depending on the desired resolution, additional tests were run that were offset by an amount equal to step size divided by the resolution sought. Multiple sets of tests were conducted to obtain effective resolution of as low as $0.5^{\circ} \mathrm{C}$ in the dynamic property measurement. Some of the tests were repeated with almost identical test results, demonstrating the repeatability of the DHFMA procedure.

\section{References}

1. Farid MM, Khudhair AM, Razack SAK, et al. A review on phase change energy storage: materials and applications. Energy Convers Manag. 2004;45(9-10):1597-615.

2. Tyagi VV, Buddhi D. PCM thermal storage in buildings: a state of art. Renew Sust Energ Rev. 2007;11(6):1146-66.

3. Shapiro MM, Feldman D, Hawes DD, Banu D. PCM thermal storage in wallboard, Proc. 12th Passive Solar Conference. Portland: ISES; 1987. p. 48-58.

4. Salyer I, Sircar A. Development of PCM wallboard for heating and cooling of residential buildings. Thermal Energy Storage Research Activities Review. New Orleans: US Department of Energy; 1989.

5. Tyagi VV, Kaushik SC, Tyagi SK, Akiyama T. Development of phase change materials based microencapsulated technology for buildings: a review. Renew Sust Energ Rev. 2011;15:1373-91. 
6. Zhou D, Zhao CY, Tian Y. Review on thermal energy storage with phase change materials (PCMs) in building applications. Appl Energy. 2012;92:583-605.

7. Kosny J, Shukla N, Fallahi A. Cost analysis of simple PCMenhanced building envelopes in southern U.S. climates. Report submitted to Building Technologies Program- Building America Project, US DOE; 2012.

8. Kim J-J, Moon JW. Impact of insulation on building energy consumption, Building simulation- Eleventh International IBPSA Conference, Glasgow, Scotland: 2009.

9. Kosny J. 2006/07 Field Testing of Cellulose Fiber Insulation Enhanced with Phase Change Material, Oak Ridge National Laboratory report - ORNL/TM-2007/186; September 2008.

10. Dincer I, Rosen M. Thermal Energy Storage: Systems and Applications. John Wiley \& Sons, ISBN 9781119956624; 2011.

11. Shukla N, Cao P, Kosny J. Lab-scale Dynamic Thermal Testing of PCM-enhanced Building Materials. ASTM Selected Technical Paper (STP) 1574-Next-Generation Thermal Insulation Challenges and Opportunities. 2014.

12. Mehling H, Cabeza LF. Heat and Cold Storage with PCM : An Up to Date Introduction Into Basics and Applications. Springer; 2008. p. 95.

13. Günther E, Hiebler S, Mehling H, Redlich R. Enthalpy of Phase Change Materials as a Function of Temperature: Required Accuracy and Suitable Measurement Methods. Int J Thermophys. 2009;30:4.

14. Kosny J, Kossecka E, Yarbrough D. Use of a Heat Flow Meter to Determine Active PCM Content in an Insulation, Proceedings of the 2009 International Thermal Conductivity Conference (ITCC) and the International Thermal Expansion Symposium (ITES), Pittsburgh, PA: 2009.

15. Shukla N, Fallahi A, Kosny J. Performance Characterization of PCM Impregnated Gypsum Board for Building Applications. Energy Procedia 30, 1st International Conference on Solar Heating and Cooling for Buildings and Industry (SHC 2012); 2012.

16. Kosny J, Kossecka E, Brzezinski A, Tleoubaev A, Yarbrough D. Dynamic Thermal Performance Analysis of Fiber Insulations Containing Bio-Based Phase Change Materials (PCMs). Energy Build. 2012;52:112-131.

17. Kosny J, Yarbrough DW, Miller WA, Wilkes KE, Lee ES. Analysis of the dynamic thermal performance of fibrous insulations containing phase change materials. Presented at 11th International Conference on Thermal Energy Storage, Effstock 2009, Thermal Energy Storage for Energy Efficiency and Sustainability. Stockholm: 2009.

18. American Society for Testing and Materials (ASTM). ASTM Standard C518, Test Method for Steady-State Heat Flux Measurements and Thermal Transmission Properties by Means of the Heat Flow Meter Apparatus. ASTM; 2010. http://www.astm. org/Standards/C518.htm.

19. American Society for Testing and Materials (ASTM). ASTM Standard C1784, Standard Test Method for Using a Heat Flow Meter Apparatus for Measuring Thermal Storage Properties of Phase Change Materials and Products. ASTM; 2014. http://www. astm.org/Standards/C1784.htm. 